\section{Is COPD Control a Useful Concept? Assessing Treatment Success by Evaluating COPD-Related Health Status}

\section{¿Es útil el concepto de control de la EPOC?: evaluación del éxito terapéutico a partir de la valoración del estado de salud en relación con la EPOC}

\section{To the Editor,}

In most chronic diseases, treatment decisions are usually based on whether control has been achieved in a given patient. This concept can have some clinical utility in COPD. However, there is currently no definition of well-controlled disease, and no objective criteria to define control in COPD or any objective tools to measure it. ${ }^{1}$ In fact, it is still unclear how to evaluate response to treatment in COPD. ${ }^{2}$

In asthma, control is an important concept, because severity is assessed retrospectively from the level of treatment required to control the disease. ${ }^{3}$ However, in asthma, the concept of control is easily confused with the concept of severity, as they represent overlapping dimensions. ${ }^{4}$ This is not the case in COPD, and GOLD 2016, unlike previous versions, recommends using the Clinical COPD Questionnaire ${ }^{5,6}$ in addition to CAT and/or mMRC as a tool for evaluating symptoms and assessing COPD health status, not as a direct measure of COPD control. ${ }^{7}$

Patients with COPD seek health care mostly due to exertional dyspnoea and limitation of physical activity: breathlessness is the most common symptom limiting exercise capacity, and exercise intolerance or decreased physical activity are present from the beginning of the disease. ${ }^{8}$ The degree of physical activity is the best predictor of all-cause mortality, ${ }^{9}$ and COPD can be understood as an exercise intolerance disease that can impact daily activities. From the patient's point of view, there should be several therapeutic successes in COPD, given the different perceptions of dyspnoea, variability in physical activity and general well-being.

COPD is characterised by persistent airway limitation that is usually progressive and not fully reversible. The term COPD brings together a number of entities with different clinical and pathophysiological features, and the treatment goals are symptomatic improvement, prevention of exacerbations and disease progression. The high mortality associated with COPD is mainly due to exacerbations requiring hospitalisation. Acute exacerbations also contribute to worsening of pulmonary function, change the trajectory of the disease, and contribute to impairment of health-related

\footnotetext{
¿3 Please cite this article as: Araújo AD, Hespanhol V, Correia-de-Sousa J. ¿Es útil el concepto de control de la EPOC?: evaluación del éxito terapéutico a partir de la valoración del estado de salud en relación con la EPOC. Arch Bronconeumol. 2017. http://dx.doi.org/10.1016/j.arbres.2016.11.024
}

quality of life. Indeed, control will always be a difficult concept to define in COPD. However, based on the definition of the disease and the goals of treatment, there are probably two main domains in COPD control: a functional domain, focussed on FEV1, and a clinical domain, focussed on exacerbations.

Nevertheless, the therapeutic definition of success should not only be based on control as a biomedical concept, but rather on a multidimensional dimension, a general COPD-related health status, that should incorporate the patient's perspective, considering also the "quality of life" dimension.

As control of symptoms is insufficient to control the disease and its progression, the patient has a limited capacity to define therapeutic success in order to participate in clinical decision-making: control is thus a limiting biomedical concept. To define therapeutic success, therefore, we also need to take in account the idea of patient well-being.

COPD is a chronic and incurable disease, and although it is unlikely that most patients will remain asymptomatic, their symptoms improve with continuous bronchodilator use. The best possible improvement in symptoms and lung function, and the absence of exacerbations, seems to be more similar to the notion of controlled disease, but it is certainly part of therapeutic success. The idea of therapeutic success is useful, because it is linked to the concept of value. ${ }^{10}$ Value in medicine must be defined in terms of the patient: it is the patient's health outcomes that matter. In clinical practice, however, it is important to define and manage the determinant factors of therapeutic success in COPD. There is a need to personalise treatment strategies, ${ }^{11}$ and four goals must be achieved. First, we have to assess the patient in a multidimensional way, according to the severity of the disease, its activity, future risk and impact on the patient, including their well-being. This allows us to define treatable clinical characteristics and assess future risk, and helps us tailor treatments to individual patients. ${ }^{12,13}$ Second, we have to evaluate the patient's perspectives and beliefs about the treatment and the disease. ${ }^{14}$ Third, it is important to prescribe the correct treatment, based on the best medical evidence, taking in account pulmonary and extra pulmonary factors, the patient's perspective and their behaviours/lifestyle. And fourth, we should monitor the treatment, assess and improve adherence, ensure correct inhalation technique and monitor the patient's well-being.

Rather than assessing treatment success based merely on the level of control that has been achieved, we should move to a more comprehensive concept by assessing COPD-related health status and evaluating the changes or the maintenance of a certain level of quality of life based on pre-established treatment goals. Deciding which tool or set of tools to use is another matter and should be discussed in another paper. ${ }^{15}$

\section{Conflicts of Interest}

The authors have no conflicts of interest to declare. 


\section{References}

1. Guimarães M, Bugalho A, Oliveira S, Moita J, Marques A. COPD control: can a consensus be found? Rev Port Pneumol. 2016;22:167-76.

2. Miravitlles M. Towards a patient-oriented treatment of COPD. Rev Port Pneumol. 2016;22:73-4.

3. Global initiative for asthma. Global strategy for asthma management and prevention (Revised 2016).

4. Taylor D, Bateman E, Boulet LP, Boushey H, Busse W, Casale T, et al. A new perspective on concepts of asthma severity and control. Eur Respir J. 2008;32:545-54.

5. van der Molen T, Willemse B, Schokker S, ten Hacken N, Postma D, Juniper E. Development, validity and responsiveness of the Clinical COPD Questionnaire. Health Qual Life Outcomes. 2003;1:13.

6. Reda A, Kotz D, Kocks J, Wesseling G, van Schayck C. Reliability and validity of the clinical COPD questionnaire and chronic respiratory questionnaire. Respir Med. 2010;104:1675-82.

7. van der Molen T, Pieters W, Bellamy D, Taylor R. Measuring the success of treatment for chronic obstructive pulmonary disease-patient, physician and healthcare payer perspectives. Respir Med. 2002;96 Suppl. C: S17-21.

8. Langer D, Demeyer H, Troosters T, Gosselink R. The importance of physical activity. Eur Respir Monogr. 2015;69:224-39.

9. Waschki B, Kirstem A, Holz O, Muller K, Meyer T, Watz H, et al. Physical activity is the strongest predictor of all-cause mortality in patients with COPD: a prospective cohort study. Chest. 2011;140:331-42.

10. Kerr D. Oral presentation at 2016 ASCO Annual Meeting.

11. Roche N. Adding biological markers to COPD categorization schemes: a way towards more personalized care. Eur Respir J. 2016;47:1601-5.

12. Agusti A, Bel E, Thomas M, Vogelmeier C, Brusselle G, Holgate S, et al. Treatable traits: toward precision medicine of chronic airway diseases. Eur Respir J. 2016;43:410-9.
13. Jones R, Price D, Chavannes N, Lee A, Hyland M, Ställberg B, et al. Multicomponent assessment of chronic obstructive pulmonary disease: an evaluation of the ADO and DOSE indices and the global obstructive lung disease categories in international primary care data sets. NPJ Prim Care Respir Med. 2016;26:16010.

14. Horne R, Chapman S, Parham R, Freemantle N, Forbes A, Cooper V. Understanding patients' adherence-related beliefs about medicines prescribed for long-term conditions: a meta-analytic review of the necessity-concerns framework. PLOS ONE. 2013;8:e80633.

15. Cave A, Atkinson L, Tsiligianni I, Kaplan A. Assessment of COPD wellness tools for use in primary care: an IPCRG initiative. Int J Chron Obstruct Pulm Dis 2012;7:447-56.

Antonio Duarte Araújo, ${ }^{\mathrm{a}, \mathrm{b}, \mathrm{c}, *}$ Venceslau Hespanhol, ${ }^{\mathrm{d}}$ Jaime Correia-de-Sousa ${ }^{b, c, e}$

a Respiratory Department, H. S. - Oliveira, Guimarães, Portugal ${ }^{\mathrm{b}}$ Life and Health Sciences Research Institute (ICVS), School of

Medicine, University of Minho, Braga, Portugal

' ICVS/3B's, PT Government Associate Laboratory, Braga/Guimarães, Portugal

d Department of Pneumology, Centro Hospitalar de S. João, Faculty of Medicine (FMUP), University of Porto, Porto, Portugal

e Community Health, School of Medicine, University of Minho, Braga, Portugal

* Corresponding author.

E-mail address: duartearaujodr@sapo.pt (A.D. Araújo). 